\title{
Experimental archaeology
}

\author{
Lisa-Marie Shillito • Eva Fairnell $•$ Helen S. Williams
}

Published online: 8 January 2014

(C) Springer-Verlag Berlin Heidelberg 2014

The collection of articles presented in this issue of Archaeological and Anthropological Sciences is the result of a call for papers issued after the Sixth UK Experimental Archaeology Conference, held at the University of York in January 2012. Since the first conference was held in London in 2006, the UK Experimental Archaeology Conference has in recent years become an annual fixture (http:// experimentalarchaeology.org.uk/). The conferences enjoy a mix of presentations, posters and practical sessions, with the experiments presented ranging in scale from laboratory microscopic work to attempting to recreate artefacts and processes in the field and with discussions covering the theory, practice and value of archaeological experimentation within and beyond the academic setting.

After the conference in Exeter in 2007, a collection of papers was published as an Oxbow monograph, Experiencing Archaeology by Experiment (Cunningham et al. 2008), and the presentations given at Cardiff in 2013 are being published in EXARC Journal (http://journal.exarc.net/). This special issue of Archaeological and Anthropological Sciences journal offers an alternative platform; with its emphasis on the integration of scientific methodologies in archaeological research and a readership that may not usually consider experimental archaeology, we hope that this collection of papers reveals the scope and potential of experiments and experimentation when applied to understanding the evidence left by past human activities.

Interpreting the distribution of lithics in the context of human activity and the use of space at Lower Palaeolithic sites is confounded by fluvial redeposition of the flakes. Chu et al. (2013) used laboratory annular flumes to induce wear on freshly knapped hand axe-thinning flakes and examined the

\footnotetext{
L.-M. Shillito $(\bowtie)$

School of History, Classics and Archaeology, University of Edinburgh, William Robertson Wing, Old Medical Building, Teviot Place Edinburgh EH8 9AG, UK

e-mail:1mshillito@ed.ac.uk

E. Fairnell · H. S. Williams

Department of Archaeology, University of York, King's Manor, York YO1 7EP, UK
}

resulting abrasion using energy-dispersive X-ray spectrometry. If the taphonomic history of an artefact post-deposition can be understood such that factors other than human agency can be accounted for, the evidence from contributing human activities can be seen with more clarity.

In the study of Smallwood (2013), microscopy is used to examine abrasion patterns on Clovis lithics after they had been used in impact experiments. Such use-wear analyses can be used to build up a body of data that can be used as comparenda when considering the function and life history of archaeological artefacts. Similarly, Bradfield and Brand (2013) used a stereomicroscope to examine macro-fractures and other usewear patterning on bone points. As well as defining parameters for testing wear when the points were used as awls, Bradfield and Brand (2013) included 'accidental' breakage in their experiments, thus enabling further characterisation of the taphonomic processes that can affect an artefact, as a direct or indirect result of human activity.

Artefacts such as lithics can be ubiquitous at sites from particular time periods, as can organic remains such as hazelnut shells. Historical generalisations and assumptions made about the presence of such objects can become accepted without question, but the application of experimental archaeology can reveal subtle nuances in the human behaviour behind a deposition. López-Dóriga (2013) used a muffle furnace to control the charring of hazelnuts and compared the results for nuts broken when fresh, dried or post-charring using a stereomicroscope. Being able to recognise the sequence of events means primary and secondary depositional processes could be determined, for example, distinguishing between dried or fresh nuts being roasted for a meal or the remains of a meal being burnt as waste.

If the end product is all that is known from the archaeological record, experimentation may be vital for understanding the process and, therefore, the human behaviour, behind the production of artefacts and products. Groom et al. (2013) developed a series of experiments in order to investigate the production of birch bark tar, a product found across Europe from many early sites, without ceramic containers. While they did not manage to produce any tar themselves, their 
experiments provide insight into the cognitive and practical processes necessary for an aceramic dry distillation process.

Páez et al. (2013) carried out experiments in order to gain a better understanding of the pre-Hispanic techniques of ceramic production used by the Inkas and to shed light on why the ceramics contain a certain percentage of pyroclastic inclusions. Based on their results, they suggest that decisions made during the manufacturing process were a solution to the practicalities of using the products; the ceramic vessels would be more durable when transported over long distances to be used at important social gatherings.

After realising that all evidence of a series of smelting experiments could apparently be lost over a very short time period, Birch et al. (2013) designed a series of experiments in order to develop a more reliable means of recognising sites of iron production and working. Similar to Chu et al. (2013), they conclude that it is important to consider micro-residues in conjunction with more traditional, macro-scale, excavation methods, so that disturbed processing sites are not overlooked, and distinctions can be made between domestic and non-domestic processes.

Birch et al. (2013) suggest that further experiments could include micromorphology and chemical analyses of sediments, and this is the approach Banerjea et al. (2013) have taken to understand the use of space within a settlement. They used micromorphology techniques as well as field methods to analyse deposits from areas of known activities within reconstructed settlements. Their analyses illustrate the powerful effect of taphonomic processes, and how understanding those processes is vital in order to interpret the spatial use of buildings that are no longer extant.

Experiments of Kania (2013) are focused on one particular activity, that of spinning, in order to understand the factors that can affect the quality of the product, in this case the yarn. By analysing the quality of fibres spun on bottom-whorl drop spindles, using modern textile industry standards and an image analysis programme, ImageJ, it was apparent that the most important variable affecting the outcome was the individual spinner, rather than the fibre or whorl. This highlights the fact that behind very product and artefact that can be found in the archaeological record is a human, with a skill set of unknown quality. The greater our understanding of the variability can exist, the more informed our interpretations can be.

Hopkins (2013) outlines the evolution of her experiments focused on understanding the dyeing industry of Pompeii. Her project from the outset was interdisciplinary, but by regularly presenting and disseminating her results, she gained new insights from other specialists that she then fed back into her experimental protocol. She has presented her work at more than one UK Experimental Archaeology Conference, thus creating a positive feedback loop between dissemination, discussion and further experimentation.

Birch et al. (2013) conclude their paper by writing: 'Although specialist guidelines exist to aid investigations of archaeometallurgy, awareness of this knowledge needs to be shared beyond the sphere of archaeometallurgists and accessibility improved'. This message is equally applicable to many subdisciplines of archaeology. The range of experiments that can be used to further our understanding of human cognition and behaviour and to unravel the influence of confounding factors is vast, and the results of these experiments can enable us to recognise defining characteristics that would otherwise be overlooked, at both macro- and micro-levels, but such knowledge gained needs to be disseminated to as wide as an audience as possible and be applied appropriately. By sharing the specific details of the experiments so that they can be replicated and applied elsewhere, the knowledge base can then grow; this process is exemplified by Hopkins' work. We hope that the collection of articles presented here provide both insight and inspiration or, at least, discussion, thus facilitating our understanding of past human activities.

\section{References}

Banerjea R, Bell M, Matthews W, Brown A (2013) Applications of micromorphology to understanding activity areas and site formation processes in experimental hut floors. Archaeological and Anthropological Sciences. doi:10.1007/s12520-013-0160-5

Birch T, Scholger R, Walach G, Stremke F, Cech B (2013) Finding the invisible smelt: using experimental archaeology to critically evaluate fieldwork methods applied to bloomery iron production remains. Archaeological and Anthropological Sciences. doi:10.1007/s12520013-0141-8

Bradfield JS, Brand T (2013) Results of utilitarian and accidental breakage experiments on bone points. Archaeological and Anthropological Sciences. doi:10.1007/s12520-013-0136-5

Chu W, Thompson C, Hosfield R (2013) Micro-abrasion of flint artifacts by mobile sediments: a taphonomic approach. Archaeological and Anthropological Sciences. doi:10.1007/s12520-013-0157-0

Cunningham P, Heeb J, Paardekooper R (eds) (2008) Experiencing archaeology by experiment. Oxbow, Oxford

Groom P, Schenck T, Moéll Pedersen G (2013) Experimental explorations into the aceramic dry distillation of Betula pubescens (downy birch) bark tar. Archaeological and Anthropological Sciences. doi: 10.1007/s12520-013-0144-5

Hopkins H (2013) The importance to archaeology of undertaking and presenting experimental research: a case study using dyeing in Pompeii. Archaeological and Anthropological Sciences. doi:10. 1007/s12520-013-0159-y

Kania K (2013) Soft yarns, hard facts? Evaluating the results of a large scale hand-spinning experiment. Archaeological and Anthropological Sciences. doi:10.1007/s12520-013-0167-y

López-Dóriga IL (2013) An experimental approach to the taphonomic study of charred hazelnut remains in archaeological deposits. Archaeological and Anthropological Sciences. doi:10.1007/ s12520-013-0154-3

Páez MC, Giovanetti MA, Arnosio M (2013) Experimentation with ceramic pastes containing high amounts of pyroclastic materials: their relation to the manufacture of Inka vessels. Archaeological and Anthropological Sciences. doi:10.1007/s12520-013-0135-6

Smallwood AM (2013) Building experimental use-wear analogues for Clovis biface functions. Archaeological and Anthropological Sciences. doi:10.1007/s12520-013-0139-2 